\title{
Enhancing Teachers' Use of Web-Based Resources: A Case Study of Secondary Technology Teachers
}

\author{
Jennifer Mangan
}

\begin{abstract}
The need for teachers to develop their content knowledge and understanding of the nature of technology remains an issue for technology education in New Zealand, and although web-based resources (WBRs) offer an effective means of supporting teachers in this endeavour, and have acknowledged potential to transform education, teachers are not necessarily well prepared to integrate WBRs effectively into their pedagogy.

This research set out to investigate how teachers could be supported to enhance their classroom use of WBRs in secondary school technology education. This involved investigating the nature and extent of the participants' existing classroom practice using WBRs, designing and implementing a sustained intervention programme to support them to expand and enhance the ways in which they integrated WBRs into their technology programmes, and evaluating how and why this influenced their classroom practice. The participants - seven experienced secondary school technology teachers-were from three different schools, had a range of backgrounds, and taught a range of technological areas including food, textiles and structural technology.
\end{abstract}

The study employed an interpretive research design and qualitative research methods, and was underpinned by a sociocultural theoretical perspective. The design of the intervention was informed by literature on characteristics of effective teacher professional development in general, ICT professional development in particular, sociocultural theories of learning, and Bell and Gilbert's (1994) model of teacher professional development which emphasises the importance of addressing three dimensions of teacher development (personal, professional and social). The intervention incorporated the Technological Pedagogical Content Knowledge (TPACK) framework (Mishra \& Koehler, 2006) as a tool for communicating the complex knowledge base required for effective integration of WBRs. The framework was also used to analyse participants' developing knowledge as they integrated new ideas and approaches in the classroom.

This research concludes that when particular components are included in a professional development programme, teachers can be supported to enhance their classroom use of WBRs and to become empowered to continue their own ongoing development, even when they have limited skills and knowledge and face significant constraints. While the critical elements of the intervention were not new, the particular combination of components was unique.

The study also draws attention to the complex range of variables that can influence individual teachers as they progress in their integration of WBRs and development of TPACK. It explores, using velocity

Wilf Malcolm Institute of Educational Research, Faculty of Education, University of Waikato, Hamilton, New Zealand ISSN: 2382-0373

Permanent Research Commons link to full thesis: http://hdl.handle.net/10289/9964

(pp. 113-114) 
as an analogy, how various factors, and their interactions, impacted on the degree, and rate, of change of the teachers' integration of WBRs.

Findings indicate that in the current educational and ICT environment, and in technology education in particular, with recent curriculum and assessment changes, teachers are likely to acknowledge a need to increase and/or enhance their classroom use of ICT and are therefore willing to engage in professional development that appears relevant and manageable in their particular teaching context.

Although examples of transformative use exist, the overall impact of ICT in education remains limited despite government funding for ICT initiatives and increasing use of ICT in education. Therefore, the conclusions of this study are particularly relevant in the current educational environment. Although the research is limited in scope to integrating WBRs in technology education, it is likely that the key principles of the intervention can be more broadly applied to ICT professional development in other subject areas. 